Voix et Images

volxetimages

\title{
Bonheur d'occasion : Claude Fournier lecteur
}

\section{Gilles Thérien}

Volume 9, numéro 2, hiver 1984

Roland Giguère

URI : https://id.erudit.org/iderudit/200450ar

DOI : https://doi.org/10.7202/200450ar

Aller au sommaire du numéro

\section{Éditeur(s)}

Université du Québec à Montréal

ISSN

0318-9201 (imprimé)

1705-933X (numérique)

Découvrir la revue

Citer ce compte rendu

Thérien, G. (1984). Compte rendu de [ Bonheur d'occasion : Claude Fournier lecteur]. Voix et Images, 9(2), 171-173. https://doi.org/10.7202/200450ar d'utilisation que vous pouvez consulter en ligne.

https://apropos.erudit.org/fr/usagers/politique-dutilisation/ 


\title{
CINÉMA
}

\section{Bonheur d'occasion: Claude Fournier lecteur.}

\author{
par Gilles Thérien, Université du Québec à Montréal
}

C'est l'époque de la guerre. Les pelotons de nouveaux engagés paradent, encadrés de militaires. Sur une des rues commerçantes de St-Henri, les employées du «15థ» regardent le spectacle. Parmi elles, Florentine Lacasse, une belle fille à l'oeil pétillant, serveuse au snack-bar. Un de ses clients assidus lui propose d'aller au cinéma. C'est Jean Lévesque. Il est bâti comme une armoire, a l'air fendant et lit des livres. Le soir, Jean attend Florentine devant le cinéma. Elle tarde. Il se cache au coin de la rue. Elle arrive. Il demeure dans sa cachette. Elle l'attend jusqu'à ce que de ses amies arrivent et l'invitent à rentrer. L'échec de cette première rencontre est compensé immédiatement par un souper en ville quand Jean se sera assuré que Florentine était bien venue pour lui. Il invite Florentine dans un restaurant chic où il se sent à l'aise mais où sa compagne cadre mal dans le décor malgré sa simplicité et sa spontanéité. Après le repas, alors qu'ils marchent dans la rue, Jean décrit ses ambitions: devenir riche, quitter St-Henri pour Westmount. Il veut s'arracher de la misère, il sait comment $y$ arriver. On sent que Florentine approuve et qu'elle est prête à partager cette quête. C'est le début d'une passion chez elle qui ne trouvera pas d'écho chez Jean. Elle cherchera à rendre ce dernier jaloux en acceptant une invitation d'accompagner Emmanuel Létourneau à une danse où elle croit que Jean se trouvera. Il n'y vient pas et Emmanuel est follement amoureux de Florentine. Claude Fournier a tôt fait dans son film d'établir ce triangle fondamental.

Parallèlement, le film raconte aussi l'histoire des parents de Florentine, les Lacasse. La mère est le pivot de cette histoire. Elle est de la trempe des Donalda, des Aurore, des victimes, des boîteuses, des souffreuses qu'un Dieu juste mais impitoyable a condamnées à vivre pour le bonheur des romanciers et des cinéastes. Enfant après enfant, logis après logis, RoseAnna Lacasse traîne sa misère dans le quartier de St-Henri. Son mari, 
Azarius, est le type même du bon Québécois, paresseux sur les bords mais d'une tendresse à toute épreuve. Sa vie se passe entre le travail qu'on ne voit pas et le chômage à côté du poêle. En plus, il y a dans le personnage d'Azarius un je ne sais quoi de franciscain qui lui permet d'admirer les oiseaux sans remarquer le crottin.

Ces deux récits, une fois amorcés, vont se poursuivre en parallèle: une montée dramatique, une chute retentissante, des solutions analogues avant de se rejoindre dans une même fin. Florentine contraint Jean à lui faire un enfant (''effet est moins voulu que la cause!). Il l'abandonne et disparaît sans laisser d'adresse. Désemparée un moment, Florentine retombe sur ses pattes et épouse Emmanuel dans les deux semaines qui précèdent son départ pour le front. Rose-Anna s'aperçoit qu'elle est enceinte au moment où son mari vient encore de perdre son emploi. Ils doivent aussi quitter leur logis qui est devenu trop cher. Le drame, c'est pourtant la mort du petit Daniel. Le mariage de Florentine lui paraît suspect. Elle semble croire que sa fille pourrait être enceinte. Tous ses malheurs seront résolus d'une façon presque miraculeuse. Elle enfante un garçon qui remplacera le petit Daniel. Azarius se trouve un job qui lui permet de faire de l'argent et de «débarrasser» sa femme de sa présence: il s'engage et partira pour le front. Enfin, elle ira habiter dans un logement confortable loué pảr Florentine qui, elle aussi, se retrouve seule. Emmanuel est parti à la guerre en laissant sa jeune épouse à l'aise financièrement.

S'il a été nécessaire de reprendre ici le récit du film, c'est pour permettre au lecteur de comprendre en quel sens Claude Fournier fait une lecture à la fois fidèle et personnelle de Bonheur d'occasion. Toute une partie du roman est laissée de côté, l'histoire d'Eugène Lacasse, le fils-soldat, de même que la peinture du milieu de St-Henri centrée sur le restaurant «Les deux records». Peut-être Fournier a-t-il réservé ces parties pour le feuilleton télévisé... Sa lecture devient encore plus personnelle dans le traitement des personnages. Sa Florentine est plus en chair, moins victime que celle du roman. Rose-Anna est une femme forte moins mesquine que le même personnage de Gabrielle Roy. Avec Fournier, Bonheur d'occasion devient presque uniquement un portrait de femmes. Et ces femmes sont bien sûr conformes aux clichés entretenus sur la femme québécoise. C'est elle qui mène. Elle a toujours raison. Elle a la générosité des martyrs. L'homme, lui, est faible. C'est le cas d'Azarius et d'Emmanuel, pas méchants pour deux sous mais voués à être cocus en chair ou en esprit. Ils tirent leur valeur de l'argent qu'ils fournissent, de la sécurité qu'ils procurent. Ils ne peuvent réussir à combler la passion et les attentes de leurs femmes. Jean Lévesque, qui réussit dans la vie, ne le fait qu'en piétinant l'amour de Florentine (et sa vertu!). Il en sort disqualifié. S'il n'est pas condamné au célibat, il lui faudra épouser une Anglaise de Westmount.

Fournier choisit donc de faire des portraits, et en très gros plan. Si ce choix du gros plan correspond à un besoin de masquer l'aspect moderne du décor naturel où il tourne ou la pauvreté des reconstitutions, il engendre un 
point de vue particulier que nous dirons ici de focalisation. Cela est vrai tant en narratologie qu'en cinématographie où la lentille découpe un visage sur un fond rendu flou par la perspective de la profondeur de champ. Ici les personnages sont tellement focalisés, réduits à des visages, que tout le reste leur est subordonné: actions, milieu social, idéologie... Ils deviennent le prisme par lequel tout se juge. S'ils sourient, c'est que l'événement (qu'il n'est plus nécessaire de voir) est joyeux, s'ils pleurent (et Dieu - et Fournier - savent qu'ils en pleurent un coup!), c'est que la vie est tragique. Le spectateur n'a aucun autre choix que celui de s'approprier le jugement de ces personnages sur une vie qui lui échappe. C'est dire aussi que la distance n'existe pas... Le spectateur a toujours le nez dedans, ce qui fait de Bonheur d'occasion un film de série B, c'est-à-dire un film sans complexité où les sentiments sont marqués par l'univocité.

En ce sens, le film exploite à fond la trame fondamentale du roman, l'histoire de personnages dont la vie se déroule dans le (mélo) drame. On ne peut crier au chef-d'oeuvre mais, curieusement, ce film marche aussi bien qu'Un homme et son péché, qu'Aurore ou que le feuilleton le Survenant. Il est fait de la même étoffe. On nage dans les clichés mais tous ces clichés ont pris une apparence humaine. Ils sont rassurants. Tout se déroule comme prévu, tout est vrai, éternellement. Ici c'est la singulière vibration humaine qui prend toute l'importance. La distribution des rôles est une des mieux réussies au cinéma québécois. Les incohérences narratives disparaissent derrière les systèmes d'opposition parallèles: mère / fille, père / mari, misère / argent, bonheur / malheur... Le traitement cinématographique du roman n'innove en aucune façon. L'image est belle, le montage précis mais sans plus. La bande sonore et musicale, seule, a une importance puisqu'elle réussit à exprimer l'atmosphère rétro du film. Bonheur d'occasion est une sorte de radio-cinéma où le feuilleton et les voix l'emportent.

Claude Fournier fait une lecture peu prétentieuse de Bonheur d'occasion et en développant une trame somme toute superficielle, il rejoint ce que ce texte a de plus authentique, c'est-à-dire le récit d'une histoire émouvante selon les règles du roman populaire. On sent bien que Fournier n'a été attentif qu'à cela, qu'aux larmes mêlées de sang qui ont l'amère saveur de ce roman d'après-guerre. 